Published in: Frank Wijen, Kees Zoeteman, and Jan Pieters (eds), A handbook of globalisation and environmental policy: National government interventions in a global arena, Edward Elgar, Cheltenham, 2005, pp. 595-623.

\title{
23. Architecture of the Kyoto Protocol and Prospects for Public Climate Policy
}

\section{Frank Wijen and Kees Zoeteman ${ }^{1}$}

\section{SUMMARY}

Options for government's future climate policy are discussed as a function of the architecture of the present regime; the latter is anchored in the Kyoto Protocol, which is aimed at reducing the human impact on climate change. We describe the basic tenets of this agreement, and explain how it was realised despite the widely divergent interests. The strengths and weaknesses of the Kyoto regime, and related future opportunities and threats, are presented. The degrees of collective decision-making and international participation were the basis for exploring four scenarios (local market, local collectivity, global market, and global collectivity) and concomitant policy instruments and actors. The possibilities of enhancing participation by linking issues and creating bandwagons are discussed. We conclude that the main flaw of the Kyoto regime is its lack of appropriate incentives. To realise a more effective regime, future climate policy should be geared towards making participation more attractive and rendering compliance selfenforcing.

\footnotetext{
${ }^{1}$ We gratefully acknowledge the insightful comments by Daan van Soest, Paul van Seters, Jan Pieters, Xavier Martin, David Levy, Erwin Bulte, Sjoerd Beugelsdijk, Marcel Berk, and Theo Beckers on an earlier version, as well as research assistance by Wiebe Vos and Suzanne Verheij and financial support by the Dutch Ministry of Spatial Planning, Housing and the Environment (VROM/DGM/KVI) to conduct this study.
} 


\section{INTRODUCTION}

The Kyoto Protocol, concluded in December 1997 to address anthropogenic (i.e., human-induced) climate change, is undoubtedly the most prominent global environmental agreement. This status stems from the perception that climate change represents a major environmental problem without easy solutions, the high stakes involved for many parties, the controversial nature of the agreement, and the media coverage it has received. ${ }^{2}$ While many uncertainties persist, increasing scientific evidence points to a large human influence on global atmospheric conditions. ${ }^{3}$ This human impact is caused mainly by the combustion of fossil fuels, which gives rise to greenhouse gases (GHGs) that retain solar radiation, causing both progressive warming of the atmosphere ${ }^{4}$ and the increased occurrence of extreme weather events. These changes may have far-reaching consequences: the progressive flooding or desertification of large areas, the melting of glaciers and ice caps, major shifts in patterns and levels of economic activities, and the disappearance of a significant number of living species. The possible consequences of climate change (including the disappearance of small island states) are thus enormous, as is the impact of addressing the causes. Many constituencies have important interests in the production, marketing, and use of derivatives of fossil fuels (oil, gas, and coal). Mitigating the human impact on climate would directly affect the financial resources of countries and companies in this business. Besides, most states and economic actors would be concerned indirectly, since a large share of economic activities are supported by fossil-fuel-generated energy. As a result, major changes of production and consumption practices would be required globally.

A major impediment to action has been the global-public-good nature of the climate issue: GHG emissions from anywhere on earth contribute to the global problem, while parties taking action enjoy only a small share of the fruits. ${ }^{5}$ This misfit between loci of costs and benefits has given rise to freerider behaviour (i.e., a calculative abstention from collective action out of personal interest), reinforced by time lags between efforts and results: future generations bear the consequences of present (in)action. Another complicating factor has been the North-South divide: low-income countries have not committed themselves to action, arguing that rich nations are responsible for most of the problems and should thus take the lead.

\footnotetext{
${ }^{2}$ Grubb et al., 1999; Oberthür and Ott, 1999.

${ }^{3}$ IPCC, 1995, 2001.

${ }^{4}$ This does not imply, however, that the temperature rises around the globe. Owing to changes in gulf streams, certain regions may actually be confronted with lower temperatures (Bartsch et al., 2000; Oberthür and Ott, 1999).

${ }^{5}$ Kaul et al., 1999.
} 
Consequently, the Protocol, which ensues from negotiations between parties with divergent interests, has also been controversial in nature. Finally, regular public attention has been drawn for over a decade by the media coverage of the climate negotiations. As a result, the Kyoto Protocol has become better known among the public at large than any other environmental agreement.

Thousands of persons have been involved - directly and indirectly - in Kyoto's lengthy antecedents, laborious conclusion, and capricious aftermath: negotiators from virtually all countries, climate scientists, business lobbyists, environmental activists, and media representatives. Myriads of publications on the Kyoto Protocol have seen the light. The object of this study was not to reiterate the factual evolution of global climate policy or to provide an indepth description of Kyoto's provisions and mechanisms; these have been excellently explained elsewhere. ${ }^{6}$ The aim of this study was twofold. First, to assess the strengths and weaknesses of the climate policy regime that has emerged over the past few decades against the objective of sharply reducing the human impact on climate. Second, to explore the opportunities and threats of future climate policy given the prevailing regime - the idea being that if the present is a reflection of past developments, a future climate regime is shaped to an important extent by the present architecture. ${ }^{7}$ The Kyoto Protocol has remained for years in a critical stage, with all options (entry-into-force, collapse, and renegotiation) still open.

While drawing on different theoretical strands, we made predominant use of insights from regime theory ${ }^{8}$ and institutional theory. ${ }^{9}$ Regimes are 'sets of implicit or explicit principles, norms, rules, and decision-making procedures around which actors' expectations converge in a given area of international relations'. ${ }^{10}$ They are constituted by factors such as the interests and influences of different parties, common norms, established customs, and generated and shared knowledge. Effective regimes contribute to putting interconnected (environmental) problems higher on the political agenda, addressing (global) problems in a more comprehensive way, and formulating national policy responses. The regime approach has different (economic, legal, political, normative) dimensions, though political aspects tend to

\footnotetext{
${ }^{6}$ Bartsch et al., 2000; Depledge, 2000; Grubb et al., 1999; Oberthür and Ott, 1999.

${ }^{7}$ This is not to say that a future regime is fully determined by the present conditions, as it is also influenced by other factors, in particular the future political willingness to act.

${ }^{8}$ Haas et al., 1993; Keohane and Nye, 2001; Krasner, 1983; Young, 1994, 1999.

9 DiMaggio and Powell, 1983; Meyer and Rowan, 1977; Phillips et al., 2000; Tolbert and Zucker, 1996.

${ }^{10}$ Krasner, 1983: 2 . While regime theory applies primarily to international relations, it can easily be extended to the national context - for example, to explain group processes that cannot be legally enforced.
} 
dominate. Therefore, regime theory provides a suitable lens to conceptualise the (global) interplay of forces, ambitions, and insights in relation to the climate-change issue. Institutional theory shows significant overlap with regime theory, though it focuses more on explaining the behaviour of (groups of) individuals and organisations. Institutions can be defined as 'enforced rules, formal and informal, about what actions are required, prohibited, or permitted'. ${ }^{11}$ They constitute the basis for institutionalisation, which is 'a core process in the creation and perpetuation of enduring social groups'. ${ }^{12}$

Empirical insights were obtained through interviews and an expert panel. Between May and December 2003, in-depth interviews were conducted with 30 representatives of (national and supranational) government, business, non-governmental organisations (NGOs), and academia in Europe and North America who had all been directly or indirectly involved in the Kyoto process. Respondents were asked about their roles, the relative importance of (domestic and international) actors, the realisation of the Kyoto Protocol, its (de)merits, and its prospects. Most interviews were tape-recorded and transcribed; detailed notes were taken of the rest. The transcripts, notes, and recent newspaper excerpts were coded in Atlas/ti, a qualitative software package. ${ }^{13}$ In December 2003, a one-day workshop was attended by 20 experts from government, business, and academia. Brainstorm-and-analysis sessions were held on the present and possible future climate regimes. Salient insights from this workshop were represented in a detailed report. ${ }^{14}$ The coded excerpts and the workshop report were subsequently analysed.

The structure of this chapter is as follows. In the second section, dealing with the past and the present, we indicate the basic tenets of the Kyoto Protocol. Factors explaining the 'success' of Kyoto are then highlighted, ${ }^{15}$ followed by a description of developments since the agreement was concluded. These lead to an assessment of the strengths and weaknesses of the Kyoto regime. They constitute inputs for the third section, which focuses on future climate policy. We explore four possible climate policy scenarios, and for each scenario discuss policy instruments and the actors involved. Next, the possibilities of creating participation leverage are indicated. In the

\footnotetext{
${ }^{11}$ Prakash, 2000: 17.

12 Tolbert and Zucker, 1996: 180.

${ }^{13}$ Codes capture and bundle highlighted chunks of text around specific themes (such as 'strengths of Kyoto' or 'relative importance of stakeholders'), facilitating the subsequent analysis of these themes. See Weitzman and Miles (1995) for a description of the analytical possibilities of Atlas/ti.

${ }^{14}$ Wijen and Zoeteman, 2004.

${ }^{15}$ The 'success' refers to getting all parties to sign the Kyoto Protocol; it does not refer to its ratification or entry-into-force.
} 
final section, we draw conclusions on the opportunities and threats of future public climate policy.

\section{KYOTO’S ARCHITECTURE ${ }^{16}$}

Kyoto's organisational embedding and substantive arrangements, such as agreed prior to and during the Protocol's conclusion and further elaborated during subsequent meetings, are described in this section. The contents were analysed against the backdrop of the different interests, and the regime's (de)merits were examined.

\section{Institutions}

An international group of climate scientists, which has participated from 1988 onwards in the Intergovernmental Panel on Climate Change (IPCC), has applied major resources to investigating the human impact on climate, as well as the socio-economic consequences of climate change. Notwithstanding the complexity of the causal chains of evidence and the uncertainty of future developments, the IPCC has increasingly come to the conclusion that the human impact on atmospheric GHG concentrations is significant and that the consequences of climate change are far-reaching. ${ }^{17}$

As a result of the growing scientific evidence of the human impact, the United Nations Framework Convention on Climate Change (UNFCCC) was signed at Rio de Janeiro in 1992. This Convention was aimed at stabilising GHG concentrations at levels that are compatible with present and future socio-economic development, thus preventing dangerous human interference with the climate system. Guiding principles were also formulated: common but differentiated responsibilities and capabilities, implying that while the same objective is pursued, individual actors assume actions according to their (financial and institutional) carrying capacity. A related principle referred to consideration of the vulnerable position of developing countries. Consequently, developed countries ('Annex I Parties') committed themselves to adopting adequate national measures. The UNFCCC was endowed with a Secretariat, established in Bonn, to coordinate and file the positions of different nations and monitor their actions. The Secretariat explored possible common grounds between states in a neutral way, thus facilitating Kyoto's

\footnotetext{
${ }^{16}$ Unless indicated otherwise, factual information in this section draws on: Barrett, 1998; Bartsch et al., 2000; Grubb et al., 1999; Gupta, 2001; McGivern, 1998; Oberthür and Ott, 1999; Yamin, 1998. The design of the Kyoto Protocol was inspired by the successful Montreal Protocol, concluded in 1987, on the ban of ozone-depleting chlorofluorocarbons (Barrett, 2003).

${ }^{17}$ IPCC, 1995, 2001.
} 
preparatory negotiations, such as the annually revolving Conferences of the Parties (COPs).

The IPCC's findings greatly facilitated the conclusion of the Kyoto Protocol. After 1997, the IPCC continued to provide scientific evidence. The UNFCCC constitutes the political and legal infrastructure of the Protocol, with an active Secretariat in charge of its implementation.

\section{Targets and Mechanisms}

The overall target of the Kyoto Protocol is to reduce human-induced GHG concentrations by an average of 5.2 per cent over the period 2008-2012 ('first commitment period'), as compared with the base year, $1990 .{ }^{18}$ The net greenhouse impact is targeted: the emissions of a basket of six GHGs (of which carbon dioxide is, in absolute terms, by far the most important) ${ }^{19}$ minus the absorption of these gases by 'sinks' (mainly additional forests). In line with the principle of differentiated responsibilities, developed nation states committed themselves to individualised targets, ranging from a 28 per cent reduction to a 27 per cent increase. ${ }^{20}$ No emission ceilings were formulated for developing countries. The height of national targets was determined on the basis of past emission records (with high past levels, both in absolute and relative terms, entailing more stringent targets) and negotiation power (with large and indispensable parties obtaining modest marks). ${ }^{21}$

While it has formulated precise targets and timetables, the Kyoto regime does not prescribe any policies and measures (PAMs). This implies that nation states have the discretion to choose domestic implementation modes. Yet, the Protocol provides international compliance options. Parties which exceed their emission caps may buy off the difference from countries which have unexploited emission room ('hot air'). By creating a market for GHG emission credits ('carbon trade'), the Protocol has caused GHGs to be monetarised for the first time. Joint Implementation (JI) is another

\footnotetext{
${ }^{18}$ It is generally recognised that this target is insufficient to achieve the Climate Convention's objective, which would necessitate more than halving anthropogenic GHG emissions (Metz and Berk, 2001; Oberthür and Ott, 1999). At the same time, unaltered practices ('business-as-usual') would entail double-digit increases (Löschel and Zhang, 2002; McGivern, 1998).

${ }^{19}$ Carbon dioxide accounts for 82 per cent of GHG emissions in industrialised countries. The other regulated gases are methane (12 per cent of emissions), nitrous oxide (4 per cent), and three halocarbons (2 per cent).

${ }^{20}$ Several Northern European countries agreed upon relatively large emission-reduction targets, while several Southern European states were entitled to the largest relative increases, following an internal EU 'bubble' agreement.

${ }^{21}$ An example of a large and indispensable party is Russia, which succeeded in negotiating stabilisation, although its economic collapse and production inefficiency would have justified a major reduction of its GHG emissions.
} 
international compliance mechanism. Countries meet their national commitments by paying for (the additional costs of) emission-reduction measures implemented in other Annex I countries. A similar tool is the Clean Development Mechanism (CDM), where (subjects of) states invest in project-based reduction measures in developing countries. The Kyoto Protocol has no financial provisions for implementation in the sense of redistributing funds, apart from some assistance to developing countries (through the Global Environment Fund, GEF).

The Protocol is thus flexible as to the gases targeted (trade-offs among GHGs are allowed), the nature of measures (technical or accounting solutions), and the locus of implementation (domestically or abroad). It is also flexible as to timing: excess emissions in a particular year may be compensated afterwards, as only the cumulative emission record by 20082012 counts, while unused assigned quantities may be saved for future periods ('banking'). Non-complying parties must assume a 30 per cent reduction surcharge in the next commitment period. There are no direct financial sanctions or other enforcement mechanisms, as is the case with most international agreements.

\section{Realisation}

While realising a global agreement, involving numerous parties, on a public good with uncertain, long-term consequences is a major enterprise, the task becomes even more arduous when conflicting interests exist. Some parties (like producers of fossil fuels and cold-climate states) had articulated interests in thwarting the realisation of such a climate agreement; indeed, they actively resisted through the Global Climate Coalition. ${ }^{22}$ It is a wonder that agreement was finally reached in Kyoto among all nation states involved in the negotiations.

A major reason for Kyoto's 'success' is that the Protocol consists of elements that are crucial to the different parties and/or that do not contain stipulations against which they have prohibitive objections. No party is completely satisfied with the present, heavily compromised agreement, but it perfectly reflects the different interests defended by blocks of negotiating countries. The European Union (EU) obtained firm targets and timetables, but had to give in with respect to its desired prescription of PAMs. The United States (US) succeeded in imposing market-like instruments and sinks as well as in avoiding PAMs, but had to compromise on the involvement of developing countries. Japan, which had mostly negotiated on the side of the US and other major non-EU industrialised countries (united in the

\footnotetext{
${ }^{22}$ Levy and Egan, 2003.
} 
'JUSSCANNZ coalition' and the similar 'Umbrella group'), ${ }^{23}$ benefited from the honour of having a prestigious agreement concluded on its territory, but had to assume an emission-reduction commitment despite the relatively high energy efficiency of its economy. Other advanced industrialised countries succeeded in avoiding high emission-reduction targets, but had to accept emission ceilings. Eastern European countries and Russia, whose GHG emissions had dramatically dropped during the 1990s, also had to show political commitment, but had the prospect of political benefit (from improved relations with the EU and US) and financial pay-off (from selling hot air). The developing countries, which had joined forces in the G77, ${ }^{24}$ managed to avoid any binding commitments, but had to demonstrate moral engagement and accept that industrialised countries obtained modest targets and could avoid domestic action through international mechanisms.

Common factors also drove the Protocol's realisation. The threat of human disasters and economic disruptions, induced by progressive warming and extreme weather events, were also a major explanation of Kyoto's realisation. An increased incidence of death from heat (virtually all warm summers at higher latitudes of the last two centuries have occurred since 1980), the exponential rise in damage from weather-related catastrophes over the last forty years, and even the outright disappearance of (parts of) lowlying countries highlight the necessity to act. ${ }^{25}$ The IPCC's mounting evidence of human influence on climate, as well as indications of consequences of climate changes, had significantly raised this awareness.

The pressure to reach an agreement was also upheld by the media. Environmental NGOs, coordinating actions through the Climate Action Network (CAN), succeeded in securing ample media attention. No party wanted to become the public scapegoat of a mediatised negotiation failure; the propensity to compromise was thus enhanced. The willingness to assume dissimilar but 'fair' shares of the reduction burden was increased by scientific calculations of national and sectoral contributions to GHG concentrations. For example, the EU's burden-sharing agreement was underpinned by calculations of relative contributions, thus turning a political polemic into a scientific debate. ${ }^{26}$ Finally, Kyoto's chair, Raúl Estrada-

${ }^{23}$ The JUSSCANNZ coalition consisted of Japan, the US, Switzerland, Canada, Australia, Norway, and New Zealand, countries which for different reasons opposed a stringent climate regime. The Umbrella group was made up of the JUSSCANNZ countries except for Switzerland, together with Russia and Ukraine.

${ }^{24}$ The G77 is a group of over a hundred developing countries, negotiating as a solid block despite internal differences. For example, the OPEC nations wanted to avoid any significant actions because of their fossil-fuel interests, while the AOSIS (Association of Small Island States) countries advocated important actions because their survival was at stake owing to rising sea levels.

${ }^{25}$ Holdren, 2003.

${ }^{26}$ Phylipsen et al., 1998. 
Oyuela, skilfully exploited the potential common grounds and hammered out a success where failure was imminent.

\section{State of Affairs}

By the year 2000, the aggregate level of net GHG emissions in Annex I countries was fairly well in line with the agreed target. ${ }^{27}$ Major contributions to this relatively favourable performance came from: Eastern Europe and Russia, whose GHG emissions had dropped dramatically after the collapse of their economies in the early 1990s; the UK, which, for financial reasons, had reconverted its energy supply from coal into gas, entailing substantially lower GHG emissions; and Germany, which had modernised the energyinefficient production installations in the Eastern part of the country following reunification. Other indicators left less room for optimism. By 2001, the EU, which was responsible for 24 per cent of GHG emissions in Annex I countries, had only slightly decreased its net emissions, particularly as a result of enhanced mobility, while aggregate stabilisation at the 1990 level was projected using existing domestic PAMs. ${ }^{28}$

Other Annex I parties were also likely to underperform. By 2000, GHG emissions had risen by 14 per cent in the US (accounting for 36 per cent of Annex I emissions) and 11 per cent in Japan (responsible for 9 per cent). The emissions of developing countries, which were formally without emission caps, had increased considerably; especially the rapid economic development of large countries such as China and India had entailed significant emission increases. $^{29}$ Therefore, while the overall performance by the turn of the millennium seemed to be in line with the Protocol's target, the prospects of sharply rising global GHG emissions did not give rise to optimism.

The Kyoto Protocol enters into force when 55 per cent of the signatories representing 55 per cent of the total carbon dioxide emissions by Annex I countries have ratified it. In late 2003, the first condition had been met (120 parties had ratified the Protocol), but the second hurdle remained (the ratifying parties represented merely 44 per cent of total emissions) because the two largest emitters (the US and Russia) had not ratified the agreement. ${ }^{30}$ Given the agreement's outright political rejection in the US in 2001, the Protocol could then only enter into force if Russia (responsible for 17 per cent of Annex I emissions) ratified it. As the country had postponed this decision because of an internal conflict of interests - between those seeking

\footnotetext{
${ }^{27}$ UNFCCC, 2003a.

${ }^{28}$ European Environment Agency, 2003.

${ }^{29}$ China is the world's second largest producer of GHGs in absolute terms (Leal Arcas, 2001).

${ }^{30}$ UNFCCC, 2003b. Australia, which accounted for 2 per cent of Annex I emissions, had also failed to ratify the agreement.
} 
to attract foreign energy-efficient investments and those benefiting from the sales of fossil fuels - and the desire to capitalise on its pivotal position - by inducing the EU and the US to bid against one another, Kyoto's entry-intoforce had turned into a game of Russian roulette.

While the US and Russia frustrated the ratification of the Kyoto Protocol, the EU moved forward by creating the institutional framework to implement the Kyoto mechanisms (in particular, emission trading from 2005 onwards). It also reiterated its commitment to the Protocol, regardless of its future status. ${ }^{31}$ The European Bank for Reconstruction and Development set up an investment fund for energy-efficient projects in Eastern Europe and Russia. At the end of 2003, the political dispute between the EU, on the one hand, and the US and Russia, on the other hand, continued, as a result of which the Kyoto Protocol faced a highly uncertain future.

\section{(De)merits}

When the institutional embedding, targets, and mechanisms of the Kyoto Protocol, along with developments since its conclusion, are combined, the following strengths and weaknesses of the Kyoto regime can be identified against the aim of mitigating the human impact on climate change. ${ }^{32}$

\section{Strengths}

- Despite the huge divergences of interests, the Kyoto Protocol has been signed by virtually all nation states, making it a truly global environmental agreement. This creates a broad basis and an important signalling function for engaging in climate-related actions around the globe. A broad climate coalition is necessary to overcome the problems inherent in a global public good such as the climate issue, and paves the way for entering and gaining momentum in learning trajectories on emission-poor activities.

- The Kyoto regime has a solid institutional infrastructure. It is based on the UNFCCC, to which all Kyoto signatories (including the US) still formally adhere. The IPCC's extensive and sustained research has considerably expanded the knowledge base of climate change. The UNFCCC Secretariat effectively coordinates the different positions and monitors the performance of countries. Annual COP meetings attended by all parties allow for the settlement of unresolved and upcoming issues.

- Innovative, flexible instruments to reduce the costs of implementation have been created. International carbon trade, JI, and the CDM are, at least in principle, ways of making the agreement cost-effective by creating

\footnotetext{
${ }^{31}$ Wallström, 2003.

32 Barrett, 2003; Grubb et al., 1999; Leal Arcas, 2001; Metz and Berk, 2001; Oberthür and Ott, 1999.
} 
international markets where transactions are settled at the least costs. An additional benefit of these financial instruments is the monetarisation of GHG emissions. This sensitises economic agents to the costs of emissions, which is a precondition for taking financially inspired actions. In addition, JI and CDM provide opportunities to reinforce international cooperation among participating countries.

- The Kyoto Protocol has specified concrete, binding targets and timetables for industrialised countries. This implies that individual commitments cannot be waived because of elusive wording. ${ }^{33}$ While the overall reduction target of 5.2 per cent may seem modest, it represents, in the context of steadily growing national products, double-digit reductions in effective terms; it also implies some decoupling of GHG emissions from economic output.

\section{Weaknesses}

- Only a minority of nation states have committed themselves to emission ceilings. Some of these states (especially the US and Australia) have withdrawn or (as with Russia) have postponed ratification. Apart from delaying or obstructing the entry-into-force decision, this leaves a small basis for action. ${ }^{34}$ Besides, the rapidly rising emissions of developing countries have remained outside the regulative scope of the Protocol.

- Even when all parties comply with their targets, the overall level of GHG concentrations is hardly affected. Halting the human impact on climate requires much more ambitious decreases. Besides, the present targets of some countries (for instance, Russia) have been set so low that they require no effort to be met, and thus do not lead to the envisaged behavioural changes.

- Kyoto's enforcement regime is weak. While the penalty of additional future reductions in case of underperformance is foreseen, it can easily be avoided - especially because future targets (for the post-2012 period) have not yet been agreed upon. The present regime is further handicapped by the absence of an effective global enforcement organism (such as a powerful world environment organisation) or mechanism (such as financial or trade sanctions), though national parliaments or NGOs may pressurise governments to meet their targets.

\footnotetext{
${ }^{33}$ Vague or ambiguous phrasing is not uncommon in international environmental agreements, facilitating their realisation but subsequently entailing interpretation problems that hamper their implementation.

${ }^{34}$ While the US has rejected the Kyoto Protocol at the federal level, many local governments (states and municipalities) have taken significant climate-related actions. Australia has indicated that it aims at complying de facto.
} 
- Carbon trade, JI, CDM, and sinks are waivers to domestic action, because parties may comply through accounting measures instead of technical actions. ${ }^{35}$ They distract attention from the sources of GHG emissions and discourage behavioural changes and the advancement of climate-neutral technology.

- The time horizon of the first budget period (2008-2012) dissuades governments from developing long-term solutions. Parties are induced to implement short-term, incremental solutions (such as optimising existing techniques), rather than forcing costly breakthrough innovations to realise the required leapfrog improvements.

- The present regime stresses the bearing and sharing of the emissionreduction burden, rather than indicating novel (economic) opportunities that may arise from emission-poor products and processes.

- Incomplete international participation and differentiated targets entail an uneven economic playing field. This especially affects energy-intensive businesses which produce in committed countries and sell on highly competitive global markets. They are likely to insist on exemption from measures. Eventually, they may even relocate to countries with permissive climate regimes.

- The present regime is overly complex. It leads to a high administrative load, which certain (developing or emerging) nations cannot or do not wish to bear. Besides, complexity facilitates fraud. Bribery of officials is a serious risk, especially when stakes are high and opportunities for corruption are ample.

- Economic activities that cannot be easily attributed to national territories (in particular, international transport) are not covered by the Protocol, though many of these 'footloose' activities have a high climate impact.

\section{PROSPECTS FOR CLIMATE POLICY}

Effective strategies consist of turning strengths into opportunities and reducing the threats that weaknesses entail. Public climate policy should aim at creating and seizing the opportunities that the Kyoto regime provides, while minimising and managing its threats. This is a complex challenge because of the numerous intervening variables (such as economic, political, technical, and demographic developments), the future directions and magnitudes of many of which are uncertain. It is useful to consider different

\footnotetext{
${ }^{35}$ Although the Kyoto Protocol states that international mechanisms are complementary to significant domestic action (the supplementarity principle), it fails to specify the minimum share of domestically taken measures.
} 
future options, which can be explored using scenarios. ${ }^{36}$ Scenarios are internally consistent, challenging descriptions of possible futures. Their aim is not to predict the future, but to sketch and understand feasible alternatives in order to be prepared for the contingent situations in which they materialise.

As described in the next sub-section, we developed four such scenarios. Government interventions that are compatible with the different scenarios, as well as the main actors involved, are reviewed. Finally, we discuss the possibilities of raising support for climate policy.

\section{Climate Scenarios}

Establishing scenarios involves the identification of future uncertainties (given the prevailing policy question), which - after correlated factors are merged - yields two critical dimensions. We adopted the key dimensions identified by the Netherlands Bureau for Economic Policy Analysis, ${ }^{37}$ which show similarities with those of the IPCC and the United Nations Environment Programme (UNEP). ${ }^{38}$ The first dimension is the extent of international cooperation, ranging from complete national sovereignty to full-fledged international cooperation. It indicates the degree to which nation states craft their climate policy in concert with other countries. The second dimension concerns the allocation of climate-related decisions. In the extreme cases, climate policy is entirely organised either by the private sector or through public responsibilities (i.e., collective action). Confronting the two dimensions yields four scenarios, which are depicted in Figure 23.1.

\section{Local market}

In this scenario, little international cooperation concurs with private-sector organisation. The lack of international support may occur if the Kyoto Protocol does not enter into force, after which parties that ratified the Protocol earlier may no longer feel committed to their initial targets. The failure or continued postponement of Kyoto's entry-into-force may result in such a complete loss of momentum. If the Kyoto regime materialises but nation states make no effort to meet their targets, international commitment will also fall short. Knowing that the Kyoto targets cannot be effectively enforced, nation states may indulge in free-rider behaviour and abstain from taking measures, especially when these are perceived as costly or untimely (for example, when they are to be taken during an economic recession).

When markets are the locus of decision-making, climate-relevant

\footnotetext{
${ }^{36}$ De Mooij and Tang, 2003; Fahey and Randall, 1998; Van der Heijden, 1996.

${ }^{37}$ De Mooij and Tang, 2003.

${ }^{38}$ IPCC, 2001; UNEP, 2002.
} 
behaviour tends to be confined to economically attractive actions: 'no regret' measures that pay off (for example, higher fuel efficiency leading to lower energy costs) and new business opportunities (such as the development and

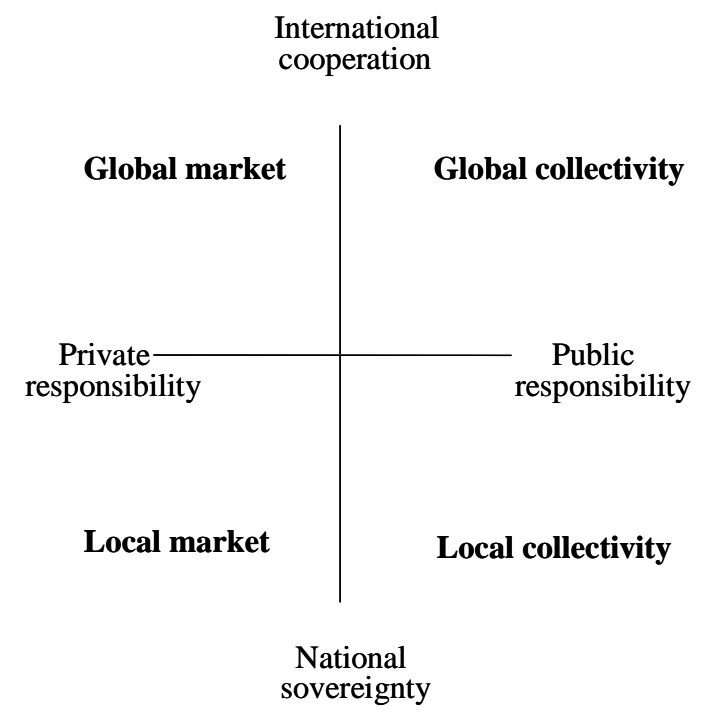

Figure 23.1 Climate policy scenarios

marketing of fuel-cell cars for areas struck by air pollution). Behavioural changes that offer no (financial) advantages to individual consumers or producers are not undertaken. Given the lack of international cooperation, costly measures involving competitive disadvantages for energy-intensive businesses exposed to international competition are particularly eschewed.

\section{Local collectivity}

This scenario involves the combination of public responsibilities and low international participation. The prevalence of national sovereignty may result from pessimism after the collapse of the Kyoto regime or the lack of incentives to comply in the absence of an effective enforcement mechanism. By contrast, some (EU) countries show a firm political and/or moral commitment to the climate cause. The asymmetry between the minority of countries that take concerted, possibly costly actions and the majority of nations that abstain from collective action leads to political tension. The proactive countries may consider the presence of 'free-riding' nations to be unfair and may experience adverse economic effects of climate-related 
measures. Industries facing international competition are hampered by the uneven playing field. Bilateral agreements among like-minded countries are concluded and regional regimes (i.e., political networks of nations with similar orientations as to climate policy) are likely to arise in the absence of one global regime. ${ }^{39}$ Such regimes turn the climate issue from a global public good into a regional club good: proactive countries collectively shield their markets from adverse competition from laggards who do not face measures that raise their production costs. ${ }^{40}$

Countries may opt for collective actions owing to political awareness (for example, because they are directly threatened by the consequences of climate change) and/or moral commitment (for instance, because conservation is a national value). Generalised local support for far-reaching public measures may, for fundamental and/or practical reasons, go together with a call for protectionist measures to guard national or regional economies against competition from 'free-riding' states.

\section{Global market}

In this scenario, many nation states commit themselves to action, which is organised through the private sector. This scenario may materialise if and when an (amended) Kyoto regime enters into force. One variant is that Russia ratifies and the US also joins the Kyoto bandwagon (for example, because non-adhesion would be costly to US businesses with international operations). Another variant is that the Kyoto Protocol does not enter into force, but is renegotiated and accepted with amendments instead. In the latter case, the UN Climate Convention is likely to be the basis for constructing such a new regime. The main objective of amending the Kyoto regime would be to get major 'missing parties' on board. In addition to the cooperation of Annex I countries that have not ratified the Protocol (especially the US, Russia, and Australia), the participation of relatively large and industrialised developing countries, which are responsible for significant and increasing contributions to GHG emissions, would then be sought. This concerns in particular China and India, but also Brazil, Indonesia, Mexico, and South Korea. The realisation of such a broad climate coalition is most likely when

\footnotetext{
39 Restrictive international trade regimes may clash with the rules of the World Trade Organization (WTO). While the regulation of environmental protection with trade-distortive effects is not forbidden by principle, it is banned when there is a suspicion of protection of local industry. As countries with much international trade wish to avoid conflict with the WTO, they will be reluctant to adopt trade-distortive measures.

${ }^{40}$ Public goods and club goods share the characteristic of non-rival consumption, but differ as to the excludability dimension: producers who do not join the club are excluded (Kölliker, 2002). To the extent that certain costs can be shared among the different participators, club goods lead to higher utility levels than do public or private goods (Schelling, 1978). It should be noted that the nature of goods is not necessarily given by technical characteristics; but it is also shaped by human intervention (Kaul et al., 2003).
} 
the ambition level of (individualised) targets is relatively low - the more easily nation states can comply, the higher their propensity to join - or when participation is attractive (for example, because it is related to significant CDM projects). Thus, a soft global regime emerges, characterised by a multilateral, market-based framework with relaxed targets and/or timetables for the present 'dropouts', and largely symbolic commitments for the new entrants.

Markets are the main mechanisms to implement a global climate agreement. They enable economic agents to settle their commitments in the most cost-effective ways. The Kyoto mechanisms lead to the emergence of new international markets, where private financial considerations determine when, where, and how much is traded and invested.

\section{Global collectivity}

In this scenario, widespread international cooperation, as favoured by the EU, takes the form of networks of public arrangements which lead to a high level of concerted action at the global level. This regime may arise as a result of increased scientific evidence of the negative consequences of climate change or the recurrence of high-impact natural catastrophes whose causes are attributed to climate change. Nation states pursue significant emission reductions, which go far beyond those agreed in the Kyoto framework and which may involve considerable financial sacrifice. Yet, there are no competitive disparities owing to global participation. Furthermore, parties without commitments in the Protocol also assume emission caps. Thus, a global regime emerges, which is based on multilateralism. The targets are not necessarily phrased in terms of national emission caps; they may also concern relative energy efficiency or focus on emission-intensive sectors.

Actions are initiated and supervised at the central level by a global climate organism. Climate policy is regarded as a public responsibility owing to a high level of (perceived) awareness of the climate-change problem. Therefore, there is general acceptance of the adverse effects on certain economic sectors and of measures involving more austere consumption practices.

\section{Policy Instruments and Parties}

The overall human impact on climate is the product of global population size, economic activity per person, the energy intensity of the average economic activity, and the carbon intensity of energy supply. ${ }^{41}$ Considering population size and the level of economic activity to be exogenous factors, public policy

\footnotetext{
${ }^{41}$ Holdren, 2003.
} 
to mitigate climate change should thus focus on reducing the energy and carbon intensities of human activities.

Climate policy should also be tailored to the characteristics of the prevailing scenario. ${ }^{42}$ When intervening, national governments should take into account the specific possibilities and constraints of the scenario that materialises. The degree of international participation determines the extent to which national commitments can be realised in a global framework. The allocation mechanism determines the extent to which climate policy is to be implemented through private or public actions. It should be noted, though, that a minimal degree of political willingness to take action is required in any scenario; if societal actors (in particular, producers and consumers) are not sensitive to the climate-change issue, all government policies and instruments are powerless. Assuming that societal actors are - or can be rendered - sufficiently sensitive, the policy implications for the different scenarios are as follows: ${ }^{43}$

\section{Local market}

In the absence of international cooperation, government has recourse to domestic measures. These measures should not be costly to industry because of international competition effects. Nor should they interfere with the sovereignty of consumers and producers. The most suitable instruments in this scenario are national communication, national subsidies for applied research and development (R\&D) of low-emission technologies, national carbon trade, and a national carbon tax. Communicating 'no regret' measures to producers and consumers involves awareness-raising, and is a way of realising both environmental and economic gains. Technology subsidies, such as those the Canadian government has granted to develop the hydrogen cell, stimulate business to realise low-emission innovations without adversely affecting existing competitive positions; they may not only absorb additional costs but also stimulate the exploration of new business opportunities. National carbon trade allows for cost-effective reductions among domestic producers without requiring changes of production modes; non-compliers can simply buy off their commitments. Finally, a carbon tax provides financial incentives for consumers to adopt lower-emission lifestyles without forcing them to change their consumption practices. This instrument does not particularly harm domestic producers, as imports are also affected.

\footnotetext{
${ }^{42}$ In this subsection, it is assumed that the climate policies of national governments aim at minimising the net national level of GHG emissions.

${ }^{43}$ Future public policy options are discussed in: Aldy et al., 2003; Barrett, 2003; Bodansky, 2003; Charnovitz, 2003; Den Elzen, 2002; Grubb et al., 2003; Heller and Shukla, 2003; ICCEPT, 2002; Kemp, 1997; Metz and Berk, 2001; Müller et al., 2003; Pershing and Tudela, 2003; Victor, 2001.
} 
The design and implementation of these policy instruments involve a small number of governing parties, in particular, the Ministry of the Environment, the Ministry of Finance, the Ministry of Economic Affairs, and the business community of nation states.

\section{Local collectivity}

In a polarised world with divergent climate regimes, proactive national policies are crafted unilaterally or in consultation with a small number of like-minded countries. Climate policy takes the form of collective action. Public policy instruments are national communication, national or regional energy-efficiency standards, national or regional covenants (i.e., negotiated agreements with industry in which targets are specified in exchange for exemption from legislation), ${ }^{44}$ and national or regional partnerships (i.e., voluntary agreements involving business, civil society, and - often government). Communication aims at making the climate-change issue a matter of (higher) common concern. Meeting stringent efficiency standards forces many producers to restructure the design of their products, during both the production phase and the consumption phase. ${ }^{45}$ Covenants also require active industry commitment, as technical measures have to be agreed upon that go beyond current practices in order to reduce GHG emissions; in contrast to the carbon-trade system, this always requires technical and organisational measures. Finally, effective partnerships require the genuine willingness and active commitment of different societal actors to engage in open discussions and accommodate their behaviour to the outcomes of such processes.

The application of these instruments involves a considerable variety of parties: the Ministries of the Environment, Economic Affairs, and Finance of a country and/or like-minded nations, national and/or regional business, national and/or regional knowledge centres, national and/or regional NGOs, and the national and/or regional public at large.

\section{Global market}

The high degree of international participation allows for the international implementation of national commitments, which take the form of marketbased actions such as envisaged in the Kyoto Protocol. Suitable policy instruments include national communication, participation in global carbon-

\footnotetext{
${ }^{44}$ Covenants may include 'bench-marking' agreements between government and local industry, indicating that local producers will be among the (world's) most energy-efficient producers in their sector in exchange for abstention from legislation.

${ }^{45}$ It should be noted that product standards are easier to control than process standards, as the former focus on characteristics of domestically available products, whereas the latter require physical controls of (foreign) production sites.
} 
trade schemes, adhesion to a global carbon-tax regime, and contribution to a global R\&D fund for low-emission technologies. Market-like instruments such as JI and CDM are applied to the extent that they are financially rewarding. Communication aims at enabling producers and consumers to make better decisions. Global carbon trade involves financial exchanges among buyers and sellers of hot air on global markets, with the possibility of enhancing cost efficiency. A global carbon tax may induce price-sensitive consumers to render their purchasing behaviour less carbon intensive, though the political feasibility of such a tax may be low. Constituting a global research fund enhances the likelihood of realising breakthrough technologies; the concomitant economies of scale are important to finance the costly R\&D in this field. JI and CDM are widely used in this scenario because of their cost-effectiveness.

These instruments require the involvement of national Ministries of the Environment, Economic Affairs, Finance, and Foreign Affairs, national and international business, as well as supranational administrative and financial bodies (such as the UNFCCC Secretariat and the GEF).

\section{Global collectivity}

As this scenario involves the highest level of international cooperation, national actions are aligned with those agreed at the global level. They are implemented through public actions. Governments intervene through national communication and participation in global energy-efficiency standards, global covenants with multinational companies, and global partnerships. Communication is geared towards informing societal actors about our common present and future. Applying stringent global standards to energy efficiency in high-impact areas is likely to have a major impact: it forces producers to 'clean up' their practices and thus creates major incentives to engage in R\&D and to meet the expected stricter standards of future generations. Global covenants with multinationals allow for regulation of 'footloose' companies which individual national governments cannot control because their activities exceed national borders. The same holds for global partnerships, in which actors have a greater propensity to take voluntary steps.

This scenario is the most comprehensive one, involving a large number and variety of parties: national Ministries of the Environment, Economic Affairs, Finance, and Foreign Affairs, national and international business, national and international knowledge centres, supranational administrative and financial bodies, national and international NGOs, and the public at large.

Table 23.1 summarises the different policy instruments and parties involved in the four scenarios. 
Table 23.1 Instruments and parties in climate policy scenarios

\begin{tabular}{|c|c|c|}
\hline Scenario & Policy instrument & Party \\
\hline Local market & $\begin{array}{l}\text { Communication } \\
\text { R\&D subsidies } \\
\text { National carbon trade } \\
\text { National carbon tax }\end{array}$ & $\begin{array}{l}\text { Ministry of the Environment } \\
\text { Ministry of Economic Affairs } \\
\text { Ministry of Finance } \\
\text { National business }\end{array}$ \\
\hline $\begin{array}{l}\text { Local } \\
\text { collectivity }\end{array}$ & $\begin{array}{l}\text { Communication } \\
\text { National/regional } \\
\text { standards } \\
\text { National/regional } \\
\text { covenants } \\
\text { National/regional } \\
\text { partnerships } \\
\end{array}$ & $\begin{array}{l}\text { Ministries of the Environment } \\
\text { Ministries of Economic Affairs } \\
\text { Ministries of Finance } \\
\text { National/regional business } \\
\text { National/reg. knowledge centres } \\
\text { National/regional NGOs } \\
\text { National/reg. public at large }\end{array}$ \\
\hline Global market & $\begin{array}{l}\text { Communication } \\
\text { Global carbon trade } \\
\text { Global carbon tax } \\
\text { Global R\&D subsidies } \\
\text { JI } \\
\text { CDM }\end{array}$ & $\begin{array}{l}\text { Ministries of the Environment } \\
\text { Ministries of Economic Affairs } \\
\text { Ministries of Finance } \\
\text { Ministries of Foreign Affairs } \\
\text { (Inter)national business } \\
\text { Supranational bodies }\end{array}$ \\
\hline $\begin{array}{l}\text { Global } \\
\text { collectivity }\end{array}$ & $\begin{array}{l}\text { Communication } \\
\text { Global standards } \\
\text { Global covenants } \\
\text { Global partnerships }\end{array}$ & $\begin{array}{l}\text { Ministries of the Environment } \\
\text { Ministries of Economic Affairs } \\
\text { Ministries of Finance } \\
\text { Ministries of Foreign Affairs } \\
\text { (Inter)national business } \\
\text { (Inter)national knowledge centres } \\
\text { Supranational bodies } \\
\text { (Inter)national NGOs } \\
\text { Global public at large }\end{array}$ \\
\hline
\end{tabular}

\section{Creating Leverage}

So far, it was assumed that a minimal willingness-to-act is present in all scenarios, though its extent was considered to be exogenously given. We next considered the motivation of societal actors to be endogenous, and explored ways of enhancing their commitment to climate-relevant measures. The literature provides two relevant ways of creating leverage. One way (issue linkage) originates in regime theory, while the other (bandwagon creation) is rooted in organisational theory (in particular, institutional theory).

\section{Linking issues}


When the climate-change problem is low on the agenda of societal actors, its position can be raised by linking it to issues that are perceived as important and urgent, provided the different issues are compatible and interdependent. ${ }^{46}$ Issue linkage has the obvious drawback of rendering a complex issue even more comprehensive, but has important potential advantages. First, when pay-offs exist in several areas, the costs of realising them can be shared. Second, connecting issues which are attributed varying degrees of importance by different parties provides the opportunity to create leverage, because parties commit themselves to acting also on low-priority issues that are tied to issues which are given high priority. Third, scope enlargement involves more parties, and thus increases possibilities to enlarge coalitions. Fourth, linking issues allows solutions to deadlocked problems to be sought by widening the scope of topics covered.

Applied to the present case, Ministries of the Environment should link climate policy to issues high on the agendas of societal actors. National climate policy may enhance economic competitiveness. Links with economic policy can be sought in terms of higher performance at the micro level (corporate cost savings resulting from the implementation of energy-efficient techniques and new market opportunities emanating from the creation of markets for low-emission products) ${ }^{47}$ and the macro level (the use of climaterelevant levies for cutting distortionary taxes). ${ }^{48} \mathrm{~A}$ double-dividend policy can be pursued to realise both environmental and economic benefits. ${ }^{49}$ This linkage strategy would be especially appealing in the local-market scenario, where economic factors are important drivers of decisions by private actors.

National climate policy can also be linked with social issues, such as health and safety. For instance, the recurrence of floods in residential areas and the death of large numbers of people from extreme temperatures enhance the domestic basis for action, not for environmental but for social reasons. In these cases, climate policy should not be put forward as a global environmental issue, but as a national political priority of an economic and/or a social nature. The global and distant nature of the climate issue can also be circumvented by tying climate policy to environmental problems which have predominantly local and short-term effects (such as air quality). While the

\footnotetext{
${ }^{46}$ Gray, 1999; Gupta and Tol, 2003; Kemfert, 2004; Keohane and Nye, 2001; Kroeze-Gil, 2003; Susskind, 1994.

${ }^{47}$ Porter and Van der Linde, 1995.

${ }^{48}$ Bovenberg and De Mooij (1994) discussed the macro-economic advantages resulting from using environmental levies to reduce the gap between labour costs and net wages.

49 The principle of such 'no regret' or 'eco-efficient' measures is not new (Grubb et al., 1999; Hall and Roome, 1996), but has not been sufficiently pushed to overcome behavioural inertia.
} 
two are not perfectly congruent, ${ }^{50}$ benefits in both areas can be realised when the consumption of fossil fuels decreases. ${ }^{51}$ This type of linking may be particularly fruitful in the local-collectivity scenario, where social issues are the domain of collective action.

Links can also be established at the international level, whereby Ministries of the Environment align their actions with those of the Ministries of Foreign and Economic Affairs. Connections can be made with international financial assistance and the reduction of trade barriers in exchange for commitments in the climate field, especially in the global-market scenario. When bilateral and multilateral financial assistance to developing and transition countries are made contingent on the climate impact of the recipient projects, economic development with a relatively moderate climate impact may be spurred. ${ }^{52}$ Likewise, nations may make their support of social issues that other countries perceive as important (for instance, security: joint abatement of terrorism or assistance in armed conflicts) contingent on collective action in the climate field; this is particularly relevant in the global-collectivity scenario. Therefore, leverage at the international level can be obtained by stressing other (than environmental) benefits of climate policy and by making national support in other areas contingent on the performance of counterparts in the climate field.

\footnotetext{
${ }^{50}$ For example, electric vehicles may lead to better local air quality (as power is generated outside the focal area), but may adversely affect climate policy (because of a relatively low energy efficiency).

${ }^{51}$ European Environment Agency, 2004.

52 Similarly, the transfer of best practices and techniques provides both environmental and economic benefits.
} 


\section{Creating bandwagons}

Bandwagons are diffusion processes whereby innovations are adopted because of the sheer number of other participants. ${ }^{53}$ Once the required critical mass has been reached, the number of adopters may rise quasiautomatically. ${ }^{54}$ Reasons for adoption include the belief that economic opportunities are otherwise foregone and the fear that others perceive nonadoption negatively. Furthermore, adoption may be a recognition of the expertise of the initiators. It may also give rise to economies of scale: high adoption rates of standards decrease relative production costs and yield positive network externalities, thus reducing the (transaction) costs stemming from different standards (such as incompatibility, additional coordination, and limited learning effects). ${ }^{55}$

The national basis for action in a climate-sceptical country may be raised once a participation threshold has been met. Ministries (of the Environment) can initiate this process of creating momentum. In the local-market scenario, a (temporarily) favourable fiscal treatment of energy-efficient technology may lead to a sufficient number of early adopters to trigger a self-reinforcing process of diffusion. In the local-collectivity scenario, national champions (i.e., highly visible, knowledgeable, and proactive societal actors) may raise the collective willingness to engage in socially or environmentally inspired actions.

At the international level, a sufficiently large number of proactive countries can induce laggards to join the bandwagon. A high degree of international participation is most likely when adhesion is beneficial to potential participants. In the global-market scenario, participation in international R\&D consortia is attractive for companies in order to share the high costs of breakthrough innovations, but also to make sure that economic opportunities are not foregone because of the lack of access to new technologies. $^{56}$ In the global-collectivity scenario, stringent collective technology standards in a sufficiently large group of proactive, wealthy countries would induce others to adhere, thus creating a self-enforcing international regime. ${ }^{57}$ For example, if major consumer markets (say, the EU plus Japan) can be served only when products meet stringent emission requirements, foreign companies and multinationals are forced to adopt the

\footnotetext{
53 Abrahamson and Rosenkopf, 1993.

${ }^{54}$ DiMaggio and Powell, 1983; Tolbert and Zucker, 1996. Examples include the expansion of supranational organisations such as the UN, the WTO, and the EU.

${ }^{55}$ Brunsson and Jacobsson, 2000.

${ }^{56}$ This implies that corporate R\&D is turned from a private into a club good: the costs and benefits no longer accrue to individual companies but to all who joined the research consortium, thus raising the utility levels of participating actors.

${ }^{57}$ Barrett, 2003. Free-riding behaviour is dissuaded, because actors have a personal interest in joining the relatively stringent regime; it is a precondition to entering major markets.
} 
more stringent standards in order to access these markets, and they may also apply them to other markets in order to reap the production and marketing economies of scale which stem from having uniform (environmentally stringent) product and process standards. ${ }^{58}$

\section{CONCLUSIONS}

We have examined the possibilities of conducting an effective future climate policy given the characteristics of the present Kyoto regime. When this regime was designed, the global-public-good nature of the climate issue had to be coped with, requiring the commitment of the global community. A diversity of - often conflicting - interests and viewpoints had to be reconciled. The ensuing Kyoto Protocol reflected the different desiderata and was, therefore, characterised by considerable complexity and ambiguity. It was signed by virtually all nation states but committed only a minority of them, thus leading to (perceived) moral and competitive disparities. Binding targets and timetables were formulated, but the Protocol's targets were insufficient to halt the cumulative process of human-induced climate change that had started over a century earlier and the agreement's time horizon was too short; besides, compliance with commitments has faced enforcement problems. Innovative, flexible instruments were designed, allowing for cost effectiveness to be enhanced and technical measures to be avoided. Developments since the Protocol's conclusion have led to global political polarisation: while some parties (especially the EU) have taken political and institutional steps towards implementation, others (the US and Australia) have formally withdrawn from the agreement or withheld their support (as with Russia), thus rendering Kyoto's global prospects highly uncertain. It should be noted, though, that adherence does not guarantee progress and withdrawal does not preclude parties from taking climate-relevant (technical) actions. Should the Protocol not enter into force, the flexible instruments, together with the solid institutional infrastructure, are the elements that are most likely to survive the present regime.

Future climate policy is contingent on a variety of factors, which affect the willingness and ability to mitigate the human impact on climate change; these include political developments (especially those in large and wealthy nation states), evolutions in the field of low-emission technologies, and the occurrence and nature of climate-related catastrophes. We explored four scenarios of future climate regimes. The local-market scenario may arise if the Kyoto regime falls apart. From the perspective of abating human-induced

${ }^{58}$ Grubb et al., 1999; Vogel, 1995. 
climate change, it is the least favourable scenario: the scope of climaterelevant actions is limited because of national sovereignty and measures are mainly confined to those that yield private economic benefits because of the dominance of market-based decisions. The global-collectivity scenario, involving a high degree of international cooperation and collective allocation decisions, may materialise after major natural calamities. This regime is relatively favourable, because concerted, politically inspired actions lead to stringent standards and sectoral agreements at the global level. The localcollectivity scenario may occur if a failure of the Kyoto regime leads to global bifurcation. In terms of climate impact, it is an intermediate option: a small number of countries prescribes relatively stringent measures, but the (geographic) scope of these actions is limited; besides, to the extent that trade-distortive effects arise, these actions may need to be mitigated to avoid economic retaliation by non-participating countries. Finally, the global market scenario may be the outcome of a renegotiated or adapted Kyoto Protocol. It is also an intermediate regime: the leverage resulting from global participation and the realisation of scale economies may lead to important progress, though actions are predominantly confined to those that are economically rewarding.

The policy measures that national governments should take are contingent on the prevailing climate regime. A local-market scenario calls for local, mainly financial policy instruments that do not significantly distort the functioning of markets; local producers and consumers retain their sovereignty. In a local-collectivity regime, more commanding instruments can be applied in concert with like-minded nations, though the (geographic) scope of relatively stringent measures is limited and governments operate in hostile international environments. International instruments can be applied in a global-market regime, though they are, by and large, still compatible with market conditions; national climate policies become subordinate to a global, mainly financial, (Kyoto-like) regime. Finally, in the globalcollectivity regime, both mandatory and voluntary actions are taken at the global level; national policy is an integral part of such measures. In the 'minimal' (local-market) scenario, relatively few actors are affected by government interventions. The variety of actors increases as decisions become more collective, while the number of parties rises with the degree of internationalisation.

Whichever future regime materialises, public climate policy will have to bear in mind what the Kyoto regime has failed to do: to capitalise on the incentives of the actors involved. The present stalemate in global public climate policy is largely the result of the perception that Kyoto commitments involve only burdens and that national compliance cannot be enforced in the absence of a powerful global regime. In order to overcome indifference and 
the temptation to indulge in free-rider behaviour, the incentives of the actors concerned should be aligned with the objectives of climate policy. Wherever possible, national governments should wield both the stick and the carrot to realise changes of production and consumption practices. When the climate problem has low political priority, it should be linked to 'hot' issues in other areas with direct and local pay-offs. Positive results may then stem not from climate-inspired actions, but from incentives to realise linked economic, social, and environmental objectives: reduced costs, new market opportunities, fewer victims of extreme weather events, improved air quality, etc. Linkage may help for developing and transition countries to raise investment and assistance funds. Connecting climate policy with air policy and atmospheric conditions is relevant in many industrialised nations.

Alternatively, actors may feel compelling incentives to participate. Once a critical threshold has been reached (for example, following commitment by the EU, Japan, and proactive US states), other private and public actors may join the climate bandwagon because they are forced to or do not wish to be excluded, thus turning the climate issue from a free-rider-struck public good into an incentive-rich club good. Powerful, self-enforcing instruments to do so are the prescription of stringent energy-efficiency standards (creating a high demand for low-emission technologies) and the establishment of R\&D consortia (enhancing the likelihood of realising technological breakthroughs). When government interventions pay more heed to providing the most appropriate incentives, future public climate policies will be more

effective and levered than the present ones.

\section{REFERENCES}

Abrahamson, E. and L. Rosenkopf (1993), 'Institutional and competitive bandwagons: Using mathematical modeling as a tool to explore innovation diffusion', Academy of Management Review, 18(3), 487-517.

Aldy, J., R. Baron, and L. Tubiana (2003), Addressing Cost: The Political Economy of Climate Change, Arlington: Pew Center on Global Climate Change.

Barrett, S. (1998), 'Political economy of the Kyoto Protocol', Oxford Review of Economic Policy, 14(4), 20-39.

Barrett, S. (2003), Environment \& Statecraft: The Strategy of Environmental TreatyMaking, Oxford: Oxford University Press.

Bartsch, U., B. Müller, and A. Aaheim (2000), Fossil Fuels in a Changing Climate: Impacts of the Kyoto Protocol and Developing Country Participation, Oxford: Oxford University Press.

Bodansky, D. (2003), Climate Commitments: Assessing the Options, Arlington: Pew Center on Global Climate Change.

Bovenberg, L. and R. De Mooij (1994), 'Environmental levies and distortionary taxation', American Economic Review, 94(4), 1085-1089. 
Brunsson, N. and B. Jacobsson (2000), A World of Standards, Oxford: Oxford University Press.

Charnovitz, S. (2003), Trade and Climate: Potential Conflicts and Synergies, Arlington: Pew Center on Global Climate Change.

Den Elzen, M. (2002), Exploring Post-Kyoto Climate Regimes for Differentiation of Commitments to Stabilise Greenhouse Gas Concentrations, report 728001020/2002, Bilthoven: RIVM (National Institute for Public Health and the Environment).

De Mooij, R. and P. Tang (2003), Four Futures of Europe, The Hague: CPB (Netherlands Bureau for Economic Policy Analysis).

Depledge, J. (2000), Tracing the Origins of the Kyoto Protocol: An Article-by-Article Textual History, Bonn: UNFCCC.

DiMaggio, P. and W. Powell (1983), 'The iron cage revisited: Institutional isomorphism and collective rationality in organizational fields', American Sociological Review, 48(April), 147-160.

European Environment Agency (2003), Greenhouse Gas Emission Trends and Projections in Europe 2003: Tracking Progress by the EU and Acceding and Candidate Countries towards Achieving Their Kyoto Protocol Targets, Environmental Issue report 36, Copenhagen: European Environment Agency.

European Environment Agency (2004), Exploring the Ancillary Benefits of the Kyoto Protocol for Air Pollution in Europe, technical report, Copenhagen: European Environment Agency.

Fahey, L. and R. Randall (1998), Learning from the Future: Competitive Foresight Scenarios, New York: John Wiley \& Sons.

Gray, B. (1999), 'The development of global environmental regimes: Organizing in the absence of authority', in D. Cooperrider and J. Dutton (eds), Organizational Dimensions of Global Change, Thousand Oaks: Sage.

Grubb, M., C. Vrolijk, and D. Brack (1999), The Kyoto Protocol: A Guide and Assessment, London: Royal Institute of International Affairs/Earth Scan.

Grubb, M., T. Brewer, B. Müller, J. Drexhage, K. Hamilton, T. Sugiyama, and T. Aiba (2003), A Strategic Assessment of the Kyoto-Marrakech System: Synthesis Report, briefing paper 6, London: Royal Institute of International Affairs.

Gupta, J. (2001), Our Simmering Planet: What to do about Global Warming?, London: Zed Books.

Gupta, J. and R. Tol (2003), 'Why reduce greenhouse gas emissions? Reasons, issuelinkages and dilemmas', in E. van Ierland, J. Gupta, and M. Kok (eds), Issues in International Climate Policy: Theory and Policy, Cheltenham: Edward Elgar.

Haas, P., R. Keohane, and M. Levy (eds) (1993), Institutions for the Earth: Sources of Effective International Environmental Protection, Cambridge: MIT Press.

Hall, S. and N. Roome (1996), 'Strategic choices and sustainable strategies', in P. Groenewegen et al. (eds), The Greening of Industry Resource Guide and Bibliography, Washington: Island Press.

Heller, T. and P. Shukla (2003), Development and Climate: Engaging Developing Countries, Arlington: Pew Center on Global Climate Change.

Holdren, J. (2003), Risks from Global Climate Change: What Do We Know? What Should We Do?, presentation at the Institutional Investors' Summit on Climate Risk, 21 November, New York: United Nations.

ICCEPT (2002), Assessment of Technological Options to Address Climate Change: A Report for the Prime Minister's Strategy Unit, London: Imperial College Centre for Energy Policy and Technology. 
IPCC (1995), 'Second assessment report of the Intergovernmental Panel on Climate Change', http://www.ipcc.ch/pub/sa(E).pdf.

IPCC (2001), 'Third assessment report of the Intergovernmental Panel on Climate Change', http://www.ipcc.ch/pub/un/syreng/spm.pdf.

Kaul, I., I. Grunberg, and M. Stern (eds) (1999), Global Public Goods: International Cooperation in the $21^{\text {st }}$ Century, New York: Oxford University Press.

Kaul, I., P. Conceição, K. Le Goulven, and R. Mendoza (eds) (2003), Providing Global Public Goods: Managing Globalization, New York: Oxford University Press.

Kemfert, C. (2004), 'Climate coalitions and international trade: Assessment of cooperation incentives by issue linkage’, Energy Policy, 32, 455-465.

Kemp, R. (1997), Environmental Policy and Technical Change: A Comparison of the Technological Impact of Policy Instruments, Cheltenham: Edward Elgar.

Keohane, R. and J. Nye (2001), Power and Interdependence, $3^{\text {rd }}$ ed., Boston: Little and Brown.

Kölliker, A. (2002), The Impact of Flexibility on the Dynamics of European Unification, $\mathrm{PhD}$ thesis, Florence: European University Institute.

Krasner, S. (ed.) (1983), International Regimes, Ithaca: Cornell University Press.

Kroeze-Gil, J. (2003), International Environmental Problems, Issue Linkage and the European Union, $\mathrm{PhD}$ thesis, Tilburg: CentER, Tilburg University.

Leal Arcas, R. (2001), 'Is the Kyoto Protocol an adequate environmental agreement to resolve the climate change problem?', European Environmental Law Review, October, 282-294.

Levy, D. and D. Egan (2003), 'A neo-Gramscian approach to corporate political strategy: Conflict and accommodation in the climate change negotiations', Journal of Management Studies, 40(4), 803-829.

Löschel, A. and Z. Zhang (2002), 'The economic and environmental implications of the US repudiation of the Kyoto Protocol and the subsequent deals in Bonn and Marrakech', Weltwirtschaftliches Archiv, 138(4), 711-746.

McGivern, B. (1998), 'Conference of the Parties to the Framework Convention on Climate Change: Kyoto Protocol: Introductory note’, International Legal Materials: Current Documents, 37(1), 22-28.

Meyer, J. and B. Rowan (1977), 'Institutionalized organizations: Formal structure and myth and ceremony', American Journal of Sociology, 83(2), 340-363.

Metz, B. and M. Berk (2001), Beyond Kyoto: Can we Stabilise at 450 ppmv $\mathrm{CO}_{2}$ ?, presentation at COP 6bis, Bonn, 25 July.

Müller, B., J. Drexhage, M. Grubb, A. Michaelowa, and A. Sharma (2003), Framing Future Commitments: A Pilot Study on the Evolution of the UNFCCC Greenhouse Gas Mitigation Scheme, Oxford: Oxford Institute for Energy Studies.

Oberthür, S. and H. Ott (1999), The Kyoto Protocol: International Climate Policy for the $21^{\text {st }}$ Century, Berlin: Springer Verlag.

Pershing, J. and F. Tudela (2003), A Long-Term Target: Framing the Climate Effort, Arlington: Pew Center on Global Climate Change.

Phillips, N., T. Lawrence, and C. Hardy (2000), 'Inter-organizational collaboration and the dynamics of institutional fields', Journal of Management Studies, 37(1), 23-43.

Phylipsen, G., J. Bode, K. Blok, H. Merkus, and B. Metz (1998), 'A Triptych sectoral approach to burden differentiation: GHG emissions in the European bubble', Energy Policy, 26(12), 929-943. 
Porter, M. and C. van der Linde (1995), 'Green and competitive: Ending the stalemate’, Harvard Business Review, September, 120-134.

Prakash, A. (2000), Greening the Firm: The Politics of Corporate Environmentalism, Cambridge: Cambridge University Press.

Schelling, T. (1978), Micromotives and Macrobehavior, New York: Norton.

Susskind, L. (1994), Environmental Diplomacy: Negotiating More Effective Global Agreements, New York: Oxford University Press.

Tolbert, P. and L. Zucker (1996), 'The institutionalization of institutional theory', in S. Clegg, C. Hardy, and W. Nord (eds), Handbook of Organization Studies, London: Sage.

UNEP (2002), ‘Global Environment Outlook 3’, http://www.unep.org/GEO, Nairobi: United Nations Environment Programme.

UNFCCC (2003a), National Communications from Parties Included in Annex I to the Convention: Compilation and Synthesis of Third National Communications, FCCC/SBI/2003/7, Bonn: United Nations Framework Convention on Climate Change.

UNFCCC (2003b), 'Kyoto Protocol: Status of Ratification', http://www.unfccc.int/ resource/kpstats.pdf, Bonn: United Nations Framework Convention on Climate Change.

Van der Heijden, K. (1996), Scenarios: The Art of Strategic Conversation, Chichester: John Wiley \& Sons.

Victor, D. (2001), The Collapse of the Kyoto Protocol and the Struggle to Slow Global Warming, Princeton: Princeton University Press.

Vogel, D. (1995), Trading up: Consumer and Environmental Regulation in a Global Economy, Cambridge: Harvard University Press.

Wallström, M. (2003), COP 9 and Beyond, speech at the Joint Informal Meeting of Environment and Energy Ministers, Montecatini, 20 July.

Weitzman, E. and M. Miles (1995), Computer Programs for Qualitative Data Analysis: A Software Sourcebook, Thousand Oaks: Sage.

Wijen, F. and K. Zoeteman (2004), 'Final report of the study "Past and Future of the Kyoto Protocol”', http://www.uvt.nl/globus/publications/publications04/publ04. 01.html, Tilburg: Globus, Tilburg University.

Yamin, F. (1998), 'The Kyoto Protocol: Origins, assessment and future challenges', Review of European Community and International Environmental Law, 7(2), 113127.

Young, O. (1994), International Governance: Protecting the Environment in a Stateless Society, Ithaca: Cornell University Press.

Young, O. (ed.) (1999), The Effectiveness of International Environmental Regimes: Causal Connections and Behavioral Mechanisms, Cambridge: MIT Press. 